\title{
Assessment of intubation procedures at reference pediatric and neonatal intensive care units
}

\author{
Fernanda P. Bonow, ${ }^{1}$ Jefferson Pedro Piva, ${ }^{2}$ \\ Pedro Celiny R. Garcia, ${ }^{3}$ Guilherme U. Eckert ${ }^{4}$
}

\begin{abstract}
Objective: To describe intubation procedures in two pediatric and two neonatal intensive care units in the city of Porto Alegre.

Methods: Cross-sectional study divided into a retrospective and a prospective phase. All intubations performed in these units during a 6-month period were considered. Data were collected by interviewing the physician responsible for the procedure and reviewing the patients' charts, including drugs administered, sedation status, number of attempts, difficulties and complications during the procedure. Data were analyzed using the $t$ test and the Mann-Whitney test for continuous variables and the chi-square test for categorical variables, considering a $\mathrm{p}<0.05$.

Results: Sedatives were administered in $89.5 \%$ of the 134 pediatric procedures and $24 \%$ of the 116 neonatal procedures $(p<0.001)$. Muscle relaxants were prescribed for $3 \%$ of the children and $0.9 \%$ of the neonates. Only $53.7 \%$ of the children and $31.9 \%$ of the neonates were considered as adequately relaxed. The children who were inadequately relaxed had more intubations attempts $(2.4 \pm 1.3 \mathrm{vs} 1.7 \pm 1.2 \mathrm{p}=0.001)$, became more hypoxemic $(20.9$ vs $5.5 \% \mathrm{p}=0.015)$ and were more difficult to intubate $(54.8 \mathrm{vs} 25 \% \mathrm{p}<0.001)$. There were more urgent cases and more intubations attempts $(2 \pm 1.2 \mathrm{vs} 1.5 \pm 0.9 \mathrm{p}=0.036)$ among the inadequately relaxed neonates. Difficulties and complications occurred in 38.8 and $28.3 \%$ of the pediatric cases and 29 and $12 \%$ of the neonatal cases, respectively.

Conclusions: There was no established routine for intubation procedures in the units studied, and the use of muscle relaxants was not usual. The absence of adequate muscle relaxation is associated with more intubation attempts, difficulties and hypoxemia during the intubation procedure.
\end{abstract}

J Pediatr (Rio J). 2004;80(5):355-62: Tracheal intubation, pediatrics, sedatives, muscle relaxant, neonate, respiratory failure.

1. PICU physician, Hospital de Pronto Socorro (HPS) and Hospital da Criança Santo Antônio, Irmandade Santa Casa de Misericórdia de Porto Alegre. Graduate student, Graduate Program in Pediatrics, Pontifícia Universidade Católica do Rio Grande do Sul (PUCRS), Porto Alegre, RS, Brazil.

2. Associate professor, Department of Pediatrics, School of Medicine, Pontifícia Universidade Católica do Rio Grande do Sul (PUCRS) and Universidade Federal do Rio Grande do Sul (UFRGS). Associate chief of the Pediatric Intensive Care Unit, Hospital São Lucas da PUCRS, Porto Alegre, RS, Brazil.

3. Associate professor, Department of Pediatrics, School of Medicine, Pontifícia Universidade Católica do Rio Grande do Sul (PUCRS). Associate chief of the Pediatric Intensive Care Unit, Hospital São Lucas da PUCRS, Porto Alegre, RS, Brazil.

4. PICU physician.

Financial support: CAPES

Manuscript received Apr 20 2004, accepted for publication Jul 072004.

Suggested citation: Bonow FP, Piva JP, Garcia PCR, Eckert GU. Assessment of intubation procedures at reference pediatric and neonatal intensive care units. J Pediatr (Rio J). 2004;80:355-62.

\section{Introduction}

Three main forms of intubation were identified in intensive care units (ICU): a) without medication, b) using just sedatives and pain relief in isolation, c) rapid sequence intubation (RSI). ${ }^{1-3}$ While a single procedural protocol does not exist, there is consensus that the ideal conditions for intubation to be considered safe include total suppression of the reflexes (cough, vomit and laryngeal reflexes) and of movement (voluntary or involuntary) together with the use of techniques to prevent passive regurgitation. ${ }^{2}$

Intubation without medication is acceptable only for cases of cardiorespiratory arrest or for patients in deep coma. ${ }^{3,4}$ While it is possible to perform the procedure using only sedatives, without muscle relaxants, the doses of these medications that are required to achieve the ideal conditions for intubation (muscle relaxation) are generally very large, 
making the time required for the procedure longer. This leads to a greater incidence of complications and provokes increased risk of adverse effects from the high doses employed. 5,6

Currently, RSI has been gaining prominence as a means of eradicating the suffering and attenuate the physiological responses of children and adults resulting from laryngoscopy and tracheal tube insertion, through the use of a number of different medications with complementary effects and more appropriate dosages. ${ }^{5-9}$ There is not yet, however, any consensus on the use of medication for the intubation of newborns. ${ }^{10,11}$

In addition to adequate sedation, securing an airway also depends on the ability, training and clinical judgment of the treating doctor. In order for training to be considered effective, with an average success rate of $90 \%$, something around 60 intubation attempts are necessary. 5,12 In our country there is no formal intubation training program in the majority of medical courses or residencies, meaning that many doctors learn intubation in clinical practice. The intubation failure rate for people in training is around $50 \%$ for the first 10 attempts, which is extremely high compared with the $0.035 \%$ achieved by specialists in theatre and $1 \%$ in emergencies. ${ }^{10,13}$

Based on these findings we believe that there is a great deal of variability in the intubation routines at pediatric and neonatal intensive care units (PICUs and NICUs). Thus, the objective of this study was to analyze the tracheal intubation procedure at model PICUs and NICUs in Porto Alegre in terms of the medication used, the degree of sedation and any associated difficulties and complications.

\section{Methods}

A cross-sectional study was performed at the PICUs and NICUs of the PUCRS Hospital São Lucas and the Irmandade Santa Casa de Misericórdia de Porto Alegre (ISCMPA). Tracheal intubation procedures were included in the study if performed between the end of December 2002 and the start of March 2003 (retrospective stage) or from the start of March to the end of June 2003 (prospective stage) at the selected ICUs and pediatric infirmaries (when run by the ICU team), whose doctors agreed to participate in the research project. Only intubations performed or supervised by the researchers were excluded.

The retrospective phase consisted of reviewing the medical records of all intubations that took place at the two pediatric ICUs during the study period and extracting from them the general patient characteristics and information on the medication employed to achieve sedation, pain relief and muscle relaxation during the procedure. The prospective phase was performed at the four ICUs (two neonatal and two pediatric) by means of (a) standardized interview with the senior doctor responsible for the intubation during the 48 hours immediately after the procedure; (b) completion of the protocol with data from medical records, vital signs charts and the first $x$-ray performed after intubation of the patient.
Primary outcomes assessed were: the use of medication (sedatives analgesics and muscle relaxants), the degree of muscle relaxation, the number of intubation attempts, the difficulties encountered and complications resulting from the procedure. The degree of muscle relaxation was estimated by means of questions on the presence of movements of the extremities, jaw rigidity or cough during the first intubation attempt. If the responsible doctor referred to any of these findings (cough, movements of arms or legs and jaw rigidity), resulted in the case being defined as having had inadequate muscle relaxation. Complications detected at the point of intubation or by the first post-intubation $x$-ray were described. Hypotension was defined as the presence of reduced arterial pressure during the intubation procedure in a patient with previously normal pressure, requiring therapeutic measures (volumetric expansion or vasoactive drug). Persistent hypoxemia was defined as saturation dropping below $85 \%$ during the intubation maneuvers, refractive to attempts at reversal with valve-bag-mask ventilation. Urgent intubations were all those cases involving cardiorespiratory arrest, bradycardia, apnea, cyanosis or accidental extubation. Intubations were classed as difficult when three or more attempts were required and/or those where the treating doctor judged them to be so.

Assuming a failure rate of around $10 \%$ for intubations performed by trained professionals and, assuming that the resident doctors perform the majority of these procedures, we estimated a probable failure rate of $30 \%$ with tolerance of $5 \%$, accepting an $\alpha$ error of 0.05 and a $B$ error of $20 \%$, and, in this manner, calculated a sample size of 120 pediatric patients and 120 newborns.

The retrospective stage of the study was designed to detect possible changes to the use of sedatives and muscle relaxants that might have been motivated by the prospective data collection. In response to the sufficient sample size, to the higher quality of the data collected in the prospective phase and to the fact that no pattern of prescribing change was detected between the two phases, we decided to study and analyze just the data from the prospective stage.

Quantitative variables with normal distribution were expressed as arithmetic means and standard deviations (DP), with groups being compared with Student's $t$ test for two independent samples. In cases of samples with asymmetrical distribution, medians and 25-75 interquartile ranges were used with the Mann-Whitney test. Qualitative variables were expressed in percentages and the chisquare test was used for possible comparisons. For all comparisons alpha cutoff was 0.05 .

The project was analyzed and approved by the scientific and ethics committees at the two institutions. An individual free and informed consent form was given to each doctor, guaranteeing the confidentiality of the data and was signed by the majority of treating and resident doctors before data collection. Irrespective of whether they had already given signed consent, each doctor was asked to give verbal permission anew at each interview, which is to say that the doctors were at liberty to do the interview or not. 


\section{Results}

\section{Characteristics}

Two hundred and ninety-seven procedures were analyzed during the 6-month study period, being 47 during the retrospective phase and 250 during the prospective stage. Four procedures were excluded because they had been supervised by the researchers themselves. Since the retrospective data collection had been restricted to intubations performed during the summer at the PICUs and covered a shorter period than the prospective phase, the number of intubations was considerably lower than during the prospective stage. There were no differences between the retrospective and prospective stages either in terms of the general characteristics of the patients (with the exception of median age $=9$ months versus 18 months $p=0.002)$ or in relation to the use and doses of intubation medication ( $97 \%$ of the patients in the retrospective study received sedatives versus $89.5 \%$ of the prospective PICU patients, $\mathrm{p}=0.01$ ).

The 250 tracheal intubation procedures performed during the 3 months of the prospective phase were distributed as follows (Table 1): 134 in PICU involving 83 children between 9 days and 17 years old (median $=1.5$ years) and 116 in NICU involving 69 babies with ages varying from 0 to 117 days (median $=2$ days). Patient characteristics were uniform across the two PICUs, while for the NICUs there were differences between the two units in terms of proportion of elective intubations ( $56.2 \%$ were urgent cases at one NICU versus $88.4 \%$ at the other, $\mathrm{p}<0.001)$, pre-intubation saturation $(80.3 \pm 19.7$ versus $70.9 \pm 21.4$ with $\mathrm{p}=0.02$ ), post-intubation saturation ( $96 \pm 3$ versus $89 \pm 11.4$ with $p=0.01$ ) and use of gastric probe during the procedure ( 84.9 versus $55.8 \%$, $\mathrm{p}=0.001)$. The predominant motive for intubation in both NICUs was pleural and pulmonary problems (53.4 versus $48.8 \% \mathrm{p}=0.12$ ). Intubations at the NICUs had lower pre-intubation saturation ( $p=0.007$ ), lower incidence of intubations with guaranteed venous access $(p=0.027)$ and a greater tendency to urgent intubations $(p=0.05)$ when compared with those at the PICUs.

\section{Medication}

Sedative and pain relief medication was used in $89.5 \%$ ( $n=120$ ) on the intubations performed at the PICUs and in just $23.3 \%(n=27)$ of those performed at NICUs $(p<0.001)$. There was a significant difference between the two different NICUs with respect of the use of sedatives during the intubation procedure (35.6 versus $2.3 \%$; $p<0.001$ ).

Table 1 - General characteristics of tracheal intubation procedures performed at PICU and NICU

\begin{tabular}{|c|c|c|c|}
\hline Characteristic & $\begin{array}{c}\text { PICU } \\
n=134\end{array}$ & $\begin{array}{c}\text { NICU } \\
n=116\end{array}$ & $\mathbf{p}$ \\
\hline Median age (25-75\% interquartile) & $18 m(4 m-8 y)$ & $2(1-17) *$ & - \\
\hline Weight $(\mathrm{kg})$ median ( $25-75 \%$ interquartile) & $9(4.9-21)$ & $1.2(0.9-2.2)$ & - \\
\hline Urgency intubation: $\mathrm{n}(\%)^{\dagger}$ & $74(55.2)$ & $79(68.1)$ & 0.05 \\
\hline Previous saturation (\%) mean \pm SD & $83.9 \pm 18.9$ & $76.9 \pm 20.7$ & 0.007 \\
\hline $\begin{array}{l}\text { Length of hospital stay/intubation (days) - } \\
\text { median ( } 25-75 \% \text { interquartile) }\end{array}$ & $2(1-9.8)$ & $2(1-17)$ & 0.361 \\
\hline Orotracheal route $\mathrm{n}(\%)$ & $122(91.1)$ & $76(65.5)$ & $<0.001$ \\
\hline Venous access $\mathrm{n}(\%)$ & $131(97.7)$ & $105(90.5)$ & 0.027 \\
\hline Gastric probe n (\%) & $106(79.1)$ & $86(74.1)$ & 0.436 \\
\hline \multicolumn{4}{|l|}{ Intubation reason $\neq \mathrm{n}(\%)$} \\
\hline Pleuropulmonary alterations & $71(53)$ & $60(51.7)$ & 0.942 \\
\hline Upper airways obstruction & $23(17.1)$ & $3(2.6)$ & $<0.001$ \\
\hline Shock & $12(8.9)$ & $4(3.4)$ & 0.129 \\
\hline CRA/bradycardia & $4(3)$ & $5(4.3)$ & 0.736 \\
\hline Apnea & $7(5.2)$ & $22(18.9)$ & $<0.001$ \\
\hline Coma/Neuromuscular alteration & $20(14.9)$ & $10(8.6)$ & 0.181 \\
\hline Tube exchange & $21(15.6)$ & $12(10.4)$ & 0.292 \\
\hline Accidental extubation & $11(8.2)$ & $22(18.9)$ & 0.020 \\
\hline Surfactant use & 0 & $16(13.8)$ & - \\
\hline Other & $10(7.4)$ & $8(6.9)$ & - \\
\hline
\end{tabular}

* Age in days.

$\dagger$ Percentage including all procedures performed at PICU and NICU.

‡ Each patient can have more than a reason for intubation.

$\mathrm{PICU}=$ pediatric intensive care unit; $\mathrm{NICU}=$ neonatal intensive care $u$ nit; $\mathrm{GA}=$ gestational age; $\mathrm{PRISM}=$ Pediatric Risk of Mortality; CRA = cardiorespiratory arrest. 
Approximately $15 \%(n=18)$ of the procedures on newborn babies were performed with the use of morphine, $10.4 \%$ $(n=12)$ with diazepam and $0.8 \%(n=1)$ with fentanyl.

At the PICUs, however, the use of diazepam predominated, followed by morphine and thiopental. There were differences $(p<0.001)$ between the PICUs with respect of the drugs employed- with midazolam and fentanyl predominating in one ICU while in the other diazepam and morphine predominated.

Muscle relaxants were used in just $3 \%(n=4)$ of the procedures on pediatric patients and $0.9 \%(n=1)$ of those on neonates, with pancuronium being used in all five cases (Table 2).

Atropine was used prophylactically in $72.4 \%(n=97)$ of intubations on children, observing differences between the two pediatric units $(47.5$ versus $82.9 \% ; p<0.001)$. None of the NICU patients had previously received atropine.

\section{Degree of sedation}

Based on information provided by the doctors, $53.7 \%$ $(n=72)$ of the pediatric patients were defined as having been adequately relaxed during the procedure compared with $31.9 \%(n=37)$ of the neonates $(p<0.001)$ (Table 3$)$.

Neither in the procedures performed at PICUs nor those performed at NICUs were there any significant differences between the groups classified as having adequate and inadequate muscle relaxation in terms of age, sex, preintubation saturation, post-intubation saturation, PRISM (PICU) and gestational age (NICU). The motive for intubation showed a greater incidence of tube changes among the pediatric patients defined as adequately relaxed (23.6 versus $6.4 \% ; \mathrm{p}=0.016)$.

Among the newborns, the inadequate muscle relaxation subset contained more urgent cases $(60.8$ versus $39.2 \%$; $p=0.023$ ) while this finding was not observed among the pediatric cases.

In the PICUs, the patients with inadequate muscle relaxation received a greater number of sedative drugs ( 98.4 versus $81.9 \% ; p=0.004$ ), larger doses of benzodiazepines and morphine, and were given thiopental more times. This phenomenon was not observed for the newborns, except in respect of the total number of drugs used which was greater among those who had been inadequately sedated (Table 4).

\section{Intubation attempts}

An average of $2 \pm 1.3$ intubation attempts were made at the PICUs in each procedure, with $24 \%(n=31)$ requiring three or more attempts. The success rate by level of training was $65 \%$ for second year residents $(46 / 70), 81.6 \%$ for third years (40/49) and $100 \%$ for treating doctors (48/48). Patients exhibiting adequate muscle relaxation were intubated at the first attempt in $59.7 \%$ of cases $(n=43)$ whereas this was possible in just $17.7 \%(n=11)$ of those with inadequate muscle relaxation $(p<0.001)$.

WE observed an average of $1.9 \pm 1.2$ intubation attempts per patient in the cases at the NICUs, with three or more attempts occurring in $24.2 \%(n=28)$ of cases. Analyzing by

Table 2 - Medication used for intubation at PICU and NICU

\begin{tabular}{|c|c|c|c|}
\hline Medication* & $\begin{array}{c}\text { PICU } \\
n=134\end{array}$ & $\begin{array}{c}\text { NICU } \\
n=116\end{array}$ & $\mathbf{p}$ \\
\hline $\begin{array}{l}\text { Diazepam n (\%) } \\
\text { Dose }^{\ddagger} \mathrm{mg} / \mathrm{kg}\end{array}$ & $\begin{array}{c}85(63.5) \\
1.2 \pm 0.5\end{array}$ & $\begin{array}{c}12(10.3) \\
0.5 \pm 0\end{array}$ & $\begin{array}{l}<0.001 \\
<0.001\end{array}$ \\
\hline $\begin{array}{l}\text { Midazolam n (\%) } \\
\text { Dose } \mathrm{mg} / \mathrm{kg}\end{array}$ & $\begin{array}{l}41(30.6) \\
0.7 \pm 0.6\end{array}$ & $\begin{array}{l}0 \\
0\end{array}$ & $\begin{array}{c}<0.001 \\
-\end{array}$ \\
\hline $\begin{array}{l}\text { Morphine } \mathrm{n}(\%) \\
\text { Dose } \mathrm{mg} / \mathrm{kg}\end{array}$ & $\begin{array}{c}75(55.9) \\
0.2 \pm 0\end{array}$ & $\begin{array}{c}18(15.5) \\
0.1 \pm 0\end{array}$ & $\begin{array}{l}<0.001 \\
<0.001\end{array}$ \\
\hline $\begin{array}{l}\text { Fentanyl n (\%) } \\
\text { Dose } \mu \mathrm{g} / \mathrm{kg}\end{array}$ & $\begin{array}{c}26(19.4) \\
6.4 \pm 3\end{array}$ & $\begin{array}{c}1(0.9) \\
1 \pm 0\end{array}$ & $\begin{array}{c}<0.001 \\
0.059\end{array}$ \\
\hline $\begin{array}{l}\text { Ketamine } \mathrm{n} \mathrm{( \% )} \\
\text { Dose } \mathrm{mg} / \mathrm{kg}\end{array}$ & $\begin{array}{c}19(14.2) \\
1.7 \pm 1\end{array}$ & $\begin{array}{l}0 \\
0\end{array}$ & $\begin{array}{c}0.001 \\
-\end{array}$ \\
\hline $\begin{array}{l}\text { Thiopental n (\%) } \\
\text { Dose } \mathrm{mg} / \mathrm{kg}\end{array}$ & $\begin{array}{c}46(34.3) \\
3.5 \pm 1.7\end{array}$ & $\begin{array}{l}0 \\
0\end{array}$ & $\begin{array}{c}<0.001 \\
-\end{array}$ \\
\hline $\begin{array}{l}\text { Pancuronium n (\%) } \\
\text { Dose } \mathrm{mg} / \mathrm{kg}\end{array}$ & $\begin{array}{l}4(3) \\
0.1 \pm 0\end{array}$ & $\begin{array}{l}1(0.9) \\
0.1 \pm 0\end{array}$ & $\begin{array}{l}0.376 \\
0.617\end{array}$ \\
\hline No medication $\mathrm{n}(\%)$ & $14(10.5)$ & $89(76.7)$ & $<0.001$ \\
\hline
\end{tabular}

* Some patients used more than one type of medication.

$\dagger$ Percentage including all procedures performed at PICU and NICU.

₹ Mean total doses for each patient (dose $x$ number of times the drug was used in each procedure), including only those who received the medication (mean and SD).

$\mathrm{PICU}=$ pediatric intensive care unit; $\mathrm{NICU}=$ neonatal intensive care unit. 
level of qualification, it was observed that first year residents were successful in $35.7 \%$ of procedures (5/14), second years in $45.1 \%(14 / 31)$, third years in $98 \%(47 / 48)$ and doctors with tenure in $96.1 \%(50 / 52)$. It was found that $31.6 \%(n=25)$ of intubations performed on newborns with inadequate muscle relaxation required three or more

Table 3 - Level of muscle relaxation achieved by the patient during intubation at PICU and NICU

\begin{tabular}{lccc}
\hline $\begin{array}{l}\text { Level of } \\
\text { muscle relaxation }\end{array}$ & $\begin{array}{c}\text { PICU } \\
\mathbf{n}=\mathbf{1 3 4}\end{array}$ & $\begin{array}{c}\text { NICU } \\
\mathbf{n}=\mathbf{1 1 6}\end{array}$ & $\mathbf{p}$ \\
\hline $\begin{array}{l}\text { Adequate muscle } \\
\text { relaxation n (\%) } *\end{array}$ & $72(53.7)$ & $37(31.9)$ & $<0.001$ \\
$\begin{array}{l}\text { Inadequate muscle } \\
\text { relaxation }{ }^{\dagger}\end{array}$ & $62(46.3)$ & $79(68.1)$ & \\
$\begin{array}{l}\text { Movements of arms } \\
\text { Cough }\end{array}$ & $40(29.8)$ & $77(66.4)$ & $<0.001$ \\
Jaw rigidity & $27(20.1)$ & $5(4.3)$ & $<0.001$ \\
& $14(10.5)$ & $7(6)$ & 0.304 \\
\hline
\end{tabular}

* Percentage including all procedures performed at PICU and NICU.

$\dagger$ The patients with inadequate muscle relaxation can present with more clinical manifestations.

PICU = pediatric intensive care unit; NICU = neonatal intensive care unit. attempts, against just $8 \%(n=3)$ of those performed on newborn babies defined as adequately relaxed $(p=0.011)$.

\section{Difficulties}

Difficulties during intubation were reported in $38.9 \%$ $(n=52)$ of the pediatric cases and $29.3 \%(n=34)$ of the neonatal ones $(p=0.149)$. At the PICUs there was more difficulty intubating patients defined as having inadequate muscle relaxation ( 54.8 versus $25 \% ; p<0.001$ ). This finding was not observed for the subset of newborn babies.

\section{Complications}

Complications occurred in $28.3 \%(n=38)$ of the pediatric procedures and in $12 \%(n=14)$ of the neonatal ones $(p=0.002)$. At the PICUs there were no differences between the subsets with and without adequate muscle relaxation with respect of the overall incidence of complications resulting from intubation ( 22.2 versus $35.4 \%$ $\mathrm{p}=0.132)$. The patients with inadequate muscle relaxation did, however, exhibit more persistent hypoxemia (Table 5 ). We observed statistical differences between the two NICUs in terms of the incidence of complications (5.5 versus $23 \% ; p=0.010$ ), with the number of urgent cases being lower in the NICU that presented fewer complications (56.2 versus $88.4 \% ; p<0.001$ ).

Table 4 - Comparison between patients with adequate and inadequate muscle relaxation regarding the use and the dose of medication for intubation at PICU and NICU

\begin{tabular}{|c|c|c|c|c|c|c|}
\hline \multirow[b]{2}{*}{ Medication * } & \multicolumn{3}{|c|}{ PICU } & \multicolumn{3}{|c|}{ NICU } \\
\hline & $\begin{array}{c}\text { AMR } \\
\mathrm{n}=\mathbf{7 2}\end{array}$ & $\begin{array}{c}\text { IMR } \\
n=62\end{array}$ & $\mathbf{p}$ & $\begin{array}{c}\text { AMR } \\
n=37\end{array}$ & $\begin{array}{c}\text { IMR } \\
n=79\end{array}$ & $\mathbf{p}$ \\
\hline Midazolam n (\%) † & $18(25)$ & $23(37)$ & 0.184 & 0 & 0 & - \\
\hline Dose $\mathrm{mg} / \mathrm{kg}$ ‡ & $0.52 \pm 0.3$ & $0.9 \pm 0.8$ & 0.033 & 0 & 0 & - \\
\hline Diazepam n (\%) & $42(58.4)$ & $43(69.3)$ & 0.253 & $4(10.8)$ & $8(10.1)$ & 1.000 \\
\hline Dose $\mathrm{mg} / \mathrm{kg}$ & $1 \pm 0.5$ & $1.3 \pm 0.5$ & 0.005 & $0.5 \pm 0$ & $0.5 \pm 0$ & - \\
\hline Morphine n (\%) & $35(48.6)$ & $40(64.5)$ & 0.093 & $3(8.1)$ & 15 (19) & 0.217 \\
\hline Dose mg/kg & $0.18 \pm 0.1$ & $0.23 \pm 0.1$ & 0.017 & $0.1 \pm 0$ & $0.1 \pm 0$ & 0.426 \\
\hline Fentanyl n (\%) & $13(18.1)$ & $13(20.9)$ & 0.836 & 0 & $1(1.3)$ & 1.000 \\
\hline Dose $\mu \mathrm{g} / \mathrm{kg}$ & $6.3 \pm 2.6$ & $6.4 \pm 3.4$ & 0.475 & 0 & $1(0)$ & - \\
\hline Ketamine $\mathrm{n}(\%)$ & $14(19.4)$ & $5(8)$ & 0.102 & 0 & 0 & - \\
\hline Dose mg/kg & $1.8 \pm 1.1$ & $1.4 \pm 0.5$ & 0.205 & 0 & 0 & - \\
\hline Thiopental n (\%) & $14(19.4)$ & $32(51.6)$ & $<0.001$ & 0 & 0 & - \\
\hline Dose $\mathrm{mg} / \mathrm{kg}$ & $3.4 \pm 1.9$ & $3.6 \pm 1.6$ & 0.409 & 0 & 0 & - \\
\hline No medication n (\%) & $13(18)$ & $1(1.6)$ & 0.004 & $32(86.5)$ & $57(72.1)$ & $<0.001$ \\
\hline
\end{tabular}

* Some patients used more than one type of medication.

$\dagger$ Percentage including all procedures performed at PICU and NICU.

$\ddagger$ Mean total doses for each patient (dose $x$ number of times the drug was used in each procedure), including only those who received the medication (mean and $S D$ ).

$\mathrm{PICU}=$ pediatric intensive care unit; $\mathrm{NICU}=$ neonatal intensive care unit; $\mathrm{AMR}=$ adequate muscle relaxation; IMR = inadequate muscle relaxation. 
Table 5 - Complications that occured after intubation according to the level of muscle relaxation of patients at PICU and NICU

\begin{tabular}{lcccccc}
\hline Complications * & $\begin{array}{c}\text { AMR } \\
\mathbf{n = 7 2}\end{array}$ & $\begin{array}{c}\text { PICU } \\
\text { IMR } \\
\mathbf{n}=\mathbf{6 2}\end{array}$ & $\mathbf{p}$ & $\begin{array}{c}\text { AMR } \\
\mathbf{n = 3 7}\end{array}$ & $\begin{array}{c}\text { NICU } \\
\text { IMR } \\
\mathbf{n}=\mathbf{7 9}\end{array}$ & $\mathbf{p}$ \\
\hline Bradycardia $\mathrm{n}(\%)^{+}$ & $5(6.9)$ & 0 & 0.061 & $2(5.4)$ & $3(3.8)$ & 0.651 \\
Bleeding $\mathrm{n}(\%)$ & $2(2.8)$ & $3(4.8)$ & 0.662 & $2(5.4)$ & $4(5)$ & 1.000 \\
Hypoxemia n (\%) & $4(5.5)$ & $13(20.9)$ & 0.015 & $1(2.7)$ & $2(2.5)$ & 1.000 \\
Vomiting $\mathrm{n}(\%)$ & $3(4.2)$ & $4(6.4)$ & 0.703 & 0 & $1(1.3)$ & 1.000 \\
Hypotension $\mathrm{n}(\%)$ & $2(2.8)$ & $5(8)$ & 0.248 & 0 & 0 & - \\
Death n (\%) & $2(2.8)$ & 0 & 0.499 & 0 & 0 & - \\
Cricothyroidotomy n (\%) & $1(1.4)$ & 0 & 1.000 & 0 & 0 & - \\
Absence of complications $\mathrm{n}(\%)$ & $56(77.7)$ & $40(64.5)$ & 0.132 & $33(89.2)$ & $69(87.3)$ & 1.000 \\
\hline
\end{tabular}

* The patients may have presented more than one complication in each procedure.

$\dagger$ Percentage of the total number of patients in each group (column).

PICU = pediatric intensive care unit; NICU = neonatal intensice care unit.

$\mathrm{AMR}=$ adequate muscle relaxation; IMR = inadequate muscle relaxation

\section{Discussion}

In this study of the tracheal intubation procedure with children and newborn babies, we were able to demonstrate that: (a) there exists a wide degree of variation in the use of sedative and analgesic medication, both between the different pediatric units and between the pediatric and neonatal units, with sedatives and analgesics being used with greater frequency during procedures at the PICUs $(90 \%)$ than at the NICUs $(24 \%)$; (b) the use of muscle relaxants for intubation was below that suggested by the literature; (c) the degree of muscle relaxation obtained could be considered inadequate in a large proportion of the cases, since in almost $50 \%$ of the children and $70 \%$ of the newborn babies some type of reaction was observed during the procedure (cough, rigid jaw or movements); (d) inadequate muscle relaxation was demonstrably associated with a larger number of intubation attempts, higher incidence of difficulties and of hypoxemia during the procedure; (e) the success rate for tracheal intubation obeys a learning curve, being low among first and second year pediatrics residents $(56 \%)$ and reaching safe and satisfactory levels among third year residents and treating doctors (93.9\%); (f) $25 \%$ of the children subjected to intubation, both in the PICUs and the NICUs, required three or more attempts, which figure is greater than those found in the literature (3.2 to $20 \%) .8,14-16$

Aiming to control possible bias resulting from data collection by interview, we performed a retrospective stage in which it was observed that medication profiles were similar to those related during the prospective stage. Additionally, in order to avoid any effect from failure to remember important information we set the time limit for the interview to take place at 48 hours. One further limitation could be the fact that the majority of the intubations took place during the first semester of the year, when the residents are less experienced. Nevertheless, even assuming that the learning curve is detectably modified during the remaining period, the difficulties described really exist and must become the subject of discussion and the adoption of corrective measures. We therefore believe that the data obtained achieve methodological support and reflect, in a trustworthy manner, the true situation with respect of this procedure in these four units and, most probably, in Brazil.

Associated with the fact that there is no uniformity to the use of medications at the PICUs, we also observed that the doses given (in terms of body weight) were, in general, larger than the doses recommended in literature (Table $6) .17,18$ This may be a result of the fact that the doses envisaged in the literature are recommended for RSI induction and not with the intention of achieving total muscle relaxation, in contrast with what, probably, happened with the patients in our study. Most probably, this muscle relaxation could have been achieved in a more appropriate manner by associating a short-duration muscle relaxant.

We believe that the low level of muscle relaxant use in our sample may be a reflection of lack of experience with the use of these medications for intubation in our country, due to the lack of systematic theoretical and practical training on the subject. Furthermore, the restricted availability of short acting muscle relaxants at the ICUs studied and a possible concern with encountering a problematic airway appear to contribute to this finding. When comparisons are made with published data, we observe a frequency of RSI use in 61 to $85 \%$ of pediatric intubations in emergency rooms, ICUs and pre-hospital care services, against just $3 \%$ in our study. $9,14,19$

In February 2004, Simon et al. ${ }^{20}$ published a study evaluating the use of pre-medication for intubation in 75 pediatric and neonatal ICUs in France. They report that just 
Table 6 - Medication used for intubation at PICU compared to the usual doses for intubation in pediatrics

\begin{tabular}{lcc}
\hline Dose of medication $*$ & $\begin{array}{c}\text { PICU } \\
\mathbf{n}=\mathbf{1 3 4}\end{array}$ & Usual doses $^{\dagger}$ \\
\hline Diazepam $(\mathrm{mg} / \mathrm{kg})$ & $1.2 \pm 0.5$ & $0.1-0.2$ \\
Midazolam $(\mathrm{mg} / \mathrm{kg})$ & $0.7 \pm 0.6$ & $0.05-0.15$ \\
Morphine $(\mathrm{mg} / \mathrm{kg})$ & $0.2 \pm 0$ & $0.1-0.2$ \\
Fentanyl $(\mu \mathrm{g} / \mathrm{kg})$ & $6.4 \pm 3$ & $1-3$ \\
Ketamine $(\mathrm{mg} / \mathrm{kg})$ & $1.7 \pm 1$ & $1-2$ \\
Thiopental $(\mathrm{mg} / \mathrm{kg})$ & $3.5 \pm 1.7$ & $4-6$ \\
\hline
\end{tabular}

* Total mean dose for each patient (dose according to weight $x$ number of times the medication was used in each procedure), including only those who received medication (mean and SD).

$\dagger$ Adapted from Levin. ${ }^{17}$

PICU = pediatric intensive care unit.

$20 \%$ of these units have defined protocols for intubation sedation, with $37 \%$ of the newborn babies, $67 \%$ of the infants and $92 \%$ of the older children studied were sedated prior to the procedure. Muscle relaxants were used in just $3 \%$ of the intubations of newborns and $8 \%$ of those performed on children, similar data to those found in our study, although different from North American literature. They, in common with us, therefore concluded that there was underutilization of intubation medication and that this conduct should be reviewed in order to guarantee the safety and comfort of the patients.

Furthermore, we observed in this study that patients considered inadequately sedated required more intubation attempts, presented more complications (hypoxemia) and were more difficult to intubate. Such associations are described with frequency in the literature.6,10,14,19,21,22 In one multicenter observational study assessing pediatric intubations that took place at 11 emergency units in the United States, RSI was used for $81 \%$ of the patients, with $78 \%$ of these being intubated at the first attempt compared with $44 \%$ of those who received just sedation. ${ }^{19}$ In addition to this, rapid sequence intubation has come to be considered a safe method of airway management, even being used as salvation therapy in some intubation failure cases. ${ }^{10}$ Marvez et al. ${ }^{8}$ evaluated 46 pediatric intubations with RSI and did not describe any complications or necessity for multiple intubation attempts. Another study describing 269 neonatal intubations, of which $94 \%$ used fentanyl and succinylcholine, also did not demonstrate significant complication; almost $80 \%$ of the patients were intubated at the first attempt and only $8 \%$ required three or more attempts. ${ }^{15}$

Medication was employed much less at the NICUs than at the PICUs: just $24 \%$ of the newborns received sedatives or analgesics, and just one patient received muscle relaxation. The same appears to take place in the United Kingdom where a study evaluating neonatal unit routines found that just $33 \%$ of them habitually used pre-intubation medication, with muscle relaxants prescribed at just $8 \%$ of NICUs. The reason for not using medication, according to the British doctors, would be lack of time. ${ }^{23}$ In our sample, despite more newborns than pediatric patients having been intubated in emergency situations, few were dealt with in conditions of extreme urgency (cardiorespiratory arrest), prophylactic surfactant administration or deep coma, in which cases there really is no time nor indication for medication. Furthermore, the beneficial effects of sedation and analgesia on intracranial pressure, the risk of a damaged airway, procedure duration and patient comfort should be considered. ${ }^{15,23-25}$ Set against this there appears to be a certain reluctance to use drugs because of the pharmacokinetic and metabolic alterations that commonly occur after the third trimester of pregnancy and last until at least 6 months of age, making the definition of dosages and the safety of drugs less predictable. 26,27 A systematic review of nine neonatology studies concluded that while there is not sufficient evidence to prove the safety of the use of pre-intubation drugs with newborns, their use should be considered. ${ }^{11}$

The wide variation in drugs chosen and doses given reflects the lack of training in airway management both on medical undergraduate courses and at the start of postgraduation. It is enough to look at the intubation success rates of first and second year residents (around 50\%) and third year residents and treating doctors (near to $100 \%$ ). What is observed, therefore, is that tracheal intubation training is obtained in a non-standard manner, being performed on the field of action and involving unstable patients. Ricard-Hibon et al. ${ }^{22}$ assessing the intubation of adults before and after specific training on the technique and the use of medication (succinylcholine), concluded that the first attempt success rate ( 74 versus $55 \%$ with $p<0.01$ ) was greater and time taken to intubate $(1.4 \pm 3.2$ minutes versus $4.1 \pm 6.7$ minutes, $p<0.001$ ) was shorter after training, demonstrating the importance of specific training in airway management. 22

In the face of these results it appears obvious that the medical curriculum must adapt itself to this need, just as airway management training should be prioritized at the start of medical residency, using protocols and courses with consistent methodology. Furthermore, we believe that the medication regime (sedatives, analgesics, muscle relaxants) used for tracheal intubation in our country should be reviewed in order to afford greater comfort and safety to patients in addition to facilitating the execution of the procedure itself.

\section{References}

1. Allen GC, Stool SE. History of pediatric airway management. Otolaryngol Clin North Am. 2000;33:1-13.

2. Magnay AR. Recent advances in intubation and mechanical ventilation. Paediatr Respir Rev. 2001;2:184-94.

3. Amantéa SL, Piva JP, Rodrigues MI, Bruno F, Garcia PCR. Acesso rápido à via aérea. J Pediatr (Rio J). 2003;79 Suppl 2:127-38.

4. American Heart Association and International Liaison Committee on Resuscitation. Pediatric Advanced Life Support. Circulation. 2000;102:291-342.

5. McAllister JD, Gnauck KA. Rapid sequence intubation of the pediatric patient: fundamentals of practice. Pediatr Clin North Am. 1999;46:1249-84. 
6. Loh KS, Irish JC. Traumatic complications of intubation and other airway management procedures. Anesthesiol Clin North Am. 2002;20:953-69.

7. Roppolo LP, Vilke GM, Chan TC, Krishel S, Hayden SR, Rosen P. Nasotracheal intubation in the emergency department, revisited. J Emerg Med. 1999;17:791-9.

8. Marvez E, Weiss SJ, Houry DE, Ernst AA. Predicting adverse outcomes in a diagnosis-based protocol system for rapid sequence intubation. Am J Emerg Med. 2003;21:23-9.

9. Walls RM, Gurr DE, Kulkarni. 6294 Emergency department intubations: second report of the Ongoing National Emergency Airway Registry (NEAR) II study. Ann Emerg Med. 2000;36:S51.

10. Bair AE, Filbin MR, Kulkarni RG, Walls RM. The failed intubation attempt in the emergency department: analysis of prevalence, rescue techniques, and personnel. J Emerg Med. 2002;23: 131-40.

11. Shah V, Ohlsson A. The effectiveness of premedication for endotracheal intubation in mechanically ventilated neonates- a systematic review. Clin Perinatol. 2002;29:535-54.

12. Sullivan KJ, Kissoon N. Securing the child's airway in the emergency department. Pediatr Emerg Care. 2002;18:108-21.

13. Levitan RM, Cook-Sather, Ochroch EA. Demystifying direct laryngoscopy and intubation. Hosp Physician. 2000;36:47-59.

14. Easley RB, Segeleon JE, Haun SE, Tobias JD. Prospective study of airway management of children requiring endotracheal intubation before admission to a pediatric intensive care unit. Crit Care Med. 2000;28:2058-63.

15. Barrington KJ, Byrne PJ. Premedication for neonatal intubation. Am J Perinatol. 1998;15:213-6.

16. Thalman JJ, Rinaldo-Gallo S, MacIntyre NR. Analysis of an endotracheal intubation service provided by respiratory care practitioners. Respir Care. 1993;38:469-73.

17. Wright $S$, Morriss FC, Toro KD. Intubation and difficult airway management. In: Levin DL, Morris FC, editors. Essentials of Pediatric Intensive Care. 2nd ed. United States of America: Churchil Livingstone; 1997. p. 1387-1405.

18. Davis SL. Neuromuscular blocking agents. In: Levin DL, Morris FC, editors. Essentials of pediatric intensive care. 2nd ed. United States of America: Churchil Livingstone; 1997. p. 1736-41.
19. Sagarin MJ, Chiang V, Sakles JC, Barton ED, Wolfe RE, Vissers $\mathrm{RJ}$, et al. Rapid sequence intubation for pediatric emergency airway management. Pediatr Emerg Care. 2002;198:417-23.

20. Simon L, Trifa M, Mokhtari M, Hamza J, Treluyer JM. Premedication for tracheal intubation: a prospective survey in 75 neonatal and pediatric intensive care units. Crit Care Med. 2004;32:565-8.

21. Li J, Murphy-Lavoie H, Bugas C, Martinez J, Preston C. Complications of emergency intubation with and without paralysis. Am J Emerg Med. 1999;17:141-3.

22. Ricard-Hibon A, Chollet C, Leroy C, Marty J. Succinylcholine improves the time of performance of a tracheal intubation in prehospital critical care medicine. Eur J Anesthesiol. 2002;19:361-7.

23. Whyte S, Birrell G, Wyllie J. Premedication before intubation in UK neonatal units. Arch Dis Child Fetal Neonatal Ed. 2000;82: 38-41.

24. DeBoer SL, Peterson LV. Sedation for nonemergent neonatal intubation. Neonatal Netw. 2001;20:19-23.

25. Barrington $K$, Finer N, Etches $P$. Succinylcholine and atropine for premedication of the newborn infant before nasotracheal intubation: a randomized, controlled trial. Crit Care Med. 1998; 17:1293-6.

26. Lingen RA, Simons SHP, Anderson BJ, Tibboel D. The effects of analgesia in the vulnerable infant during the perinatal period. Clin Perinatol. 2002;29:511-34.

27. Lago PM, Piva JP, Garcia PCR, Sfoggia A, Knight G, Ramelet AS et al. Analgesia e sedação em situações de emergência e unidades de tratamento intensivo pediátrico. J Pediatr (Rio J). 2003;79 Suppl 2:223-30.

Corresponding author

Fernanda Paiva Bonow

Rua Carlos Trein Filho, 1171/702, Bela Vista

CEP 90450-120 - Porto Alegre, RS

Brazil

Phone: +55 (51) 3333.0905

E-mail: fbonow@terra.com.br 